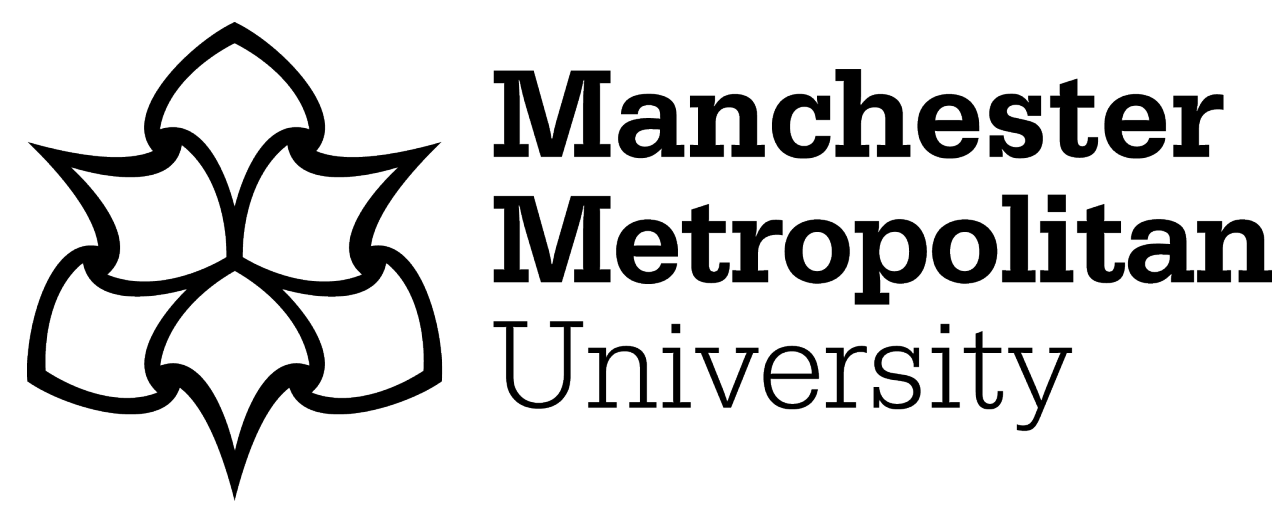

Collins, Alison and Cartwright, S (2012) Why Come Into Work III? Individual and Organisational Factors Underlying Presenteeism. Employee Relations, 34 (4). pp. 429-442. ISSN 0142-5455

Downloaded from: https://e-space.mmu.ac.uk/621653/

Version: Accepted Version

Publisher: Emerald

DOI: https://doi.org/10.1108/01425451211236850

Please cite the published version 


\title{
Why come into work ill? Individual and organizational factors underlying presenteeism
}

Alison Collins and Susan Cartwright

Centre for Organizational Health and Wellbeing, Lancaster University, Lancaster, UK

\begin{abstract}
Purpose

This paper explores the perceptions of managers and employees, in one private and one public sector organization, towards an individual's decision to go to work despite being unwell, a phenomenon known as presenteeism in the literature.
\end{abstract}

\section{Design/methodology/approach}

Qualitative interviews $(n=33)$ were used to investigate the personal beliefs and attitudes of managers and employees towards presenteeism in an attempt to understand why individuals come into work despite being unwell, rather than taking time off work.

\section{Findings}

This paper explores the factors that influence an individual's decision to come into work despite being ill. Employee's who are unwell are likely to take into consideration a combination of factors before deciding whether to come into work or take sick leave. Our findings highlight the importance of both the work environment and an individual's personal motivation, including their work ethic, on presenteeism, providing further evidence that context is important.

\section{Originality/value}

Our findings support previous research that attendance management mechanisms implement by the organization can lead to absenteeism. However, well designed and managed return to work policies can be of reciprocal benefit to both the organization and the employee.

Key words: Presenteeism, private sector, public sector

\section{Case Study}

This research is supported by a grant awarded by the BUPA Foundation 


\section{Introduction}

Presenteeism has been defined in a number of ways, however, for this paper we have adopted Aronsson and Gustafasson’s (2000:503) definition “of people, despite complaints and ill health that should prompt rest and absence from work, still turning up at their jobs". As Johns (2010) points out presenteeism can have important consequences to employees in that it may aggravate medical conditions and any reduced productivity can lead to employees being viewed as ineffective workers. Previous research by Dew et al (2005) indicates that presenteeism is based on a rational decision by individuals to come to work whilst unwell and the underlying factors that promote presenteeism differ across workplaces and occupational groups. A recent report by CBI/Pfizer (2010) estimated that the cost of employee absence in the UK to be $£ 16.8$ billion in 2009. According to the Sainsbury Centre for Mental Health the cost of presenteeism could be higher. They estimated that in terms of mental health problems alone presenteeism could account for 1.5 times the number of work days due to absenteeism, which they estimated costs UK companies $£ 15.1$ billion a year (Sainsbury Centre for Mental health, 2007). Whatever the actual ratio research suggests that presenteeism is prevalent with over $70 \%$ of working Danes (Hansen and Anderson 2008) and 47\% of Swedish police officers Leineweber et al., (2010) indicating that they have attended work whilst unwell at least once in a 12 month period.

The CBI/Ffizer (2010) study estimates that the average costs of absence are higher amongst public sector organizations than their private sector equivalents. However, research suggests that presenteeism is also higher amongst public sector employees due to employee perceptions of job insecurity, a perception they are hard to replace and a sense of responsibility to clients because of the sector they work in, namely care, welfare and education areas (Aronsson et al., 2000; Calverley et al., 2007). This qualitative study 
attempted to further understanding of why individual's go into work despite being ill and to explore the individual and organizational factors that promote presenteeism.

\section{Factors that promote presenteeism}

As a framework for research into presenteeism, Aronsson and Gustafsson's (2005) model conceptualises attendance decisions as being influenced by work-related demands and pressures and personally related demands for presence. Although research by Hansen and Anderson (2008) suggests that work-related factors may impact more on people's decision to go to work whilst ill than personal factors.

\section{Work-related demands}

The model proposed by Aronsson and Gustafsson (2005) details the work related demands for presenteeism as being replaceability, sufficient resources, conflicting demands, control over pace of work and time pressure. A number of other factors that influence presenteeism have been identified. Bockerman and Laukkanen (2009) found that presenteeism is influenced by working time arrangements to a greater extent than absenteeism. Long working hours, long working weeks, frequent overtime and a mismatch between the amount of hours wanted by the employee and actual hours worked are all considered to be factors which lead to increased presenteeism. Previous research also highlights the important role that managers play in terms of influencing presenteeism and absenteeism through their management style (Ramsey, 2006), their relationships with employees and how they implement sickness absence policies (Wynne-Jones et al., 2010; Baker-McClearn et al., 2010). 
Other mediating factors that influence presenteeism and absenteeism include job insecurity (Hansen and Anderson, 2008) and support of colleagues whereby a lack of support is associated with a greater risk of presenteeism (Leineweber et al., 2010).

Occupational group has also been found to influence presenteeism with professions in care, welfare and education having the highest levels (Aronsson et al., 2000).

\section{Personal factors}

Aronsson and Gustafsson (2005) propose individual boudarylessness (difficulty in saying no) and private-financial demands as personally related demands for presenteeism. More recent research has also found that people with financial difficulties are more likely to show presenteeism (Ashby and Mahdon, 2010) suggesting that they are under a financial pressure to attend work. However, it is likely that organizational policies in terms of whether, and to what extent, sick pay is given to staff taking sickness absence will also influence the impact of financial pressure on an individual's decision to go into work.

Teamwork has a strong influence on presenteeism as individuals are reluctant to let colleagues down (Grinyer and Singleton, 2000) and people take into consideration whether their absence will affect others (Baker-McClearn et al., 2010). However, although people may come into work whilst ill because of a responsibility to the team, people appear to experience a conflict with the decision as they do not want to pass on illness to colleagues (Ashby and Mahdon, 2010).

Other personal factors which influence presenteeism include boundarylessness and over commitment (difficulty in saying no) (Hansen and Anderson, 2008; Aronsson and Gustafsson, 2005) and conservative attitudes towards absence (Hansen and Anderson, 2008)

\section{Organizational policies}


A number of policies have been introduced by organizations to reduce short-term absence including Return to Work Interviews, home visits and the requirement for employees to keep management informed about their absence (Taylor et al., 2010). However, research by Grinyer and Singleton (2000) illustrates how organizational systems introduced to mitigate short term absence can have unintended consequences and promote both presenteeism and absenteeism. In an effort to manage absence the organization studied had introduced trigger points to highlight when staff had reached a certain level of sick leave and they would then be called in for an interview. Grinyer and Singleton (2000) found that these measures led to presenteeism because employees feared reaching these trigger points. They also found that trigger points may increase absenteeism because people were reluctant to return to work until they were sure that they had recovered from the illness in case they had to take further absence and thereby accrue two absence episodes instead of one. Thus, organizational policies introduced to reduce short-term sickness made employees resentful and stressed because staff were reluctant to take sick leave.

Policies intended to reduce absenteeism such as reducing sick pay may ultimately increase presenteeism. Chatterji and Tilley (2002:686) suggest that "any attempt at reducing the potential productivity loss from absence has to be offset against the potential productivity loss from presenteeism". However, it is difficult to gauge the effects of presenteeism because measures rely upon individuals' self-reporting when they have attended work while sick as well as their personal estimation of productivity which could be subject to distortion (Johns, 2010). Researchers also use a variety of measures which vary in complexity making it hard to make comparisons across studies (Sanderson et al., 2007). As Johns (2010) points out although studies tend to agree that greater productivity loss is associated with presenteeism 
than absenteeism there is a great deal of variation in terms of both the effects and costs with respect to presenteeism reported across studies.

The aims of this paper are to explore the perceptions and beliefs that managers and employees hold towards presenteeism, sickness absence and return to work policies to increase understanding why individuals come into work despite being unwell, rather than taking time off work. 


\section{Study Methodology and Sample}

This paper discusses findings from the qualitative analysis of interview data collected as part of a larger two year longitudinal quantitative study of presenteeism and its implication on workers' health and well being.

The research was carried out in one public sector (police force - organization 1) and one private sector organization (food manufacturer - organization 2). As part of the larger quantitative survey participants were asked to recall the number of times they were absent and the times they came into work whilst sick or injured during the previous three months. Job satisfaction was measured using the 'aspects of your job' variable from the ASSET organizational screening tool (Cartwright and Cooper, 2002). Although not directly a measure of job satisfaction the variable does correlate highly with Warr's (1990) job satisfaction scale (Faragher et al., 2004). As can be seen from table 1 organization 2 presented with lower absenteeism and presenteeism and higher job satisfaction than organization 1 and indicates that the health of employees in the private sector organization was rather better than in the public sector comparator.

\section{Insert Table 1 here}

The participants from the police force (organization 1) had previously volunteered to complete the questionnaire as part of the longitudinal study. Ninety-eight were randomly selected and invited to take part in interviews and fourteen accepted, although one interview failed to record. In total four civilians and nine serving police officers took part in the study. Due to logistic issues such as the shift times and location of participants across the county 
covered by the force, interviews with civilian and serving police officers were conducted by telephone. Further interviews were carried out with a Human Resource employee, an occupational health employee and a welfare employee face to face. Fifteen interviews were conducted with employees from a food manufacturing company (organization 2). All interviews were arranged by the organization and were conducted face to face at the production site.

In total 33 semi-structured interviews were used to gain insights into the experiences and perceptions of participants surrounding issues of presenteeism and absenteeism in their organization. The purpose of the research was explained to all participants and a consent form completed. All participants consented to the interviews being digitally recorded and all were transcribed.

The Semi-structured interviews followed a schedule which included any personal experiences of presenteeism. For example, participants were asked to reflect on the last time they came to work although they should have stayed home for health reasons, the reasons they came into work that day, the type of health impairment they would consider taking time off work, management policies surrounding absenteeism and the consequences to co-workers when individuals come into work ill and when they take sickness absence. Transcripts were categorised and coded according to the research questions or from key themes that emerged from the data following King (2004). Having categorised the data into key themes the data was refined into subthemes. In order to develop an understanding of presenteeism salient themes were identified which appeared relevant, for example because of the number of participants who mentioned it or if there was a strong emotive or expressive element to a 
participant's narrative. The findings were then presented following the key themes identified, utilising examples from interviews as required.

\section{Sickness absence policies}

The sickness absence policies of the two organizations had some similarity in procedures; both organizations had set procedures for reporting absence with the onus on the individual, periods of paid absence related to how long the individual had been employed at the organization, they also both used 'trigger' points in terms of times absence within a specific point of time for example organization 1 used three periods of absence in three months or six working days in a six month period whilst organization 2 used three periods or 5\% absence in twelve months. The two organizations also included modified duties and a phased return to work policy, working closely with the occupational health departments, to aid rehabilitation of employees. Employees at organization 1 had access to osteopaths and physiotherapists through occupational health and could join a scheme giving them access to a police convalescence home.

Organization 2 placed great emphasis on employee well-being. There was a gym on site which was free to employees and access given to families. Fitness activities are also available from lunchtime walking activities around the site, aerobics, badminton, cycling, canoeing, dancing and spinning classes. The organization also provides free fruit in the canteen and through the occupational health department provide medical check-ups for staff and health promotion measures such as smoking advice. Depending on tenure, the company also offered private health care which allows participating staff to visit private sector physiotherapists and osteopaths. Organization 2 did not pay for the first four days of sickness after that qualifying period employees were paid $90 \%$ of their normal weekly rate of pay. 


\section{Results}

\section{Organizational Policies}

As stated above both organizations used 'trigger' points in terms of times absence within a specific point of time. Hitting these trigger points resulted in the start of a disciplinary procedure. As one participant summed it up:

"You are only allowed three short blocks a year, so you've already used up two so you've only got one left for the year before you're going to get hauled over the coals" [Participant 2, female, organization1]

Participants from organization 1 particularly felt that sickness absence policies constrained people to come into work for fear of disciplinary proceedings leading ultimately to dismissal:

“I've seen people absolutely properly with flu and really ill and I'm sitting there, you need to go home, I don't want it and they say well I've had two sets of sickness I can't afford another one [Participant 11, male, organization 1]

One participant who had gone through attendance management procedures has beenreluctant to take any further sickness absence for over two years because they had been 'worried' by the process as:

“it makes you look bad even though you haven't done anything wrong" [Participant 1, female, organization 1]

The emphasis on periods of absence at organization 1 meant that if individuals came back to work too early and have to take further time off with the same condition it is be counted as two periods of absence. Two participants felt this was unfair and stated that they would take longer sickness absence to ensure they were recovered rather than returning early and then having to take extra time off: 
"Yes, I wouldn't rush back ... because like I say having it go down as two periods of sickness when it was clearly only one and I was just trying to do my best to get my work done. It did make me angry that you do get penalised trying to do your best" [Participant 6, female, organization1]

However, there appeared to be an element of manager discretion in terms of sending people home who were not fully recovered so that it would not result in their having two sickness periods on their employment record:

“I've had people where they've had one day off, come back into work, not been $100 \%$ and I've had to send them home ...because if they'd stayed they would have ended up accruing it as two occasions so to speak on their sickness record" [Participant 3, male, organization 1]

In organization 2 people returning to work after illness were given absence reviews and if they were not fully recovered they would be sent home:

"That is why we have the absence review so we can get to that detail and if it is someone trying to get back too soon and they've fallen ill again or they are not right we send them home ourselves.” [Participant 9, male, organization 2]

\section{Return to Work Policies}

The two organizations had fairly similar return to work policies, for example, both organizations had the support of an occupational health unit, utilised modified duties and a phased return to work policy to aid employees returning to work. Overall both organizations were very proactive in terms of getting people back to work through modified duties or graded return to work policies. Human resources staff from both organizations acknowledged that in terms of long term sickness it is preferable to have an employee come back to work through such return to work policies, if they are fit enough, even though they are less 
productive, than having an employee continuing to be absent from work. It was felt that the longer an individual is absent from work the longer the less likely that individual will ever return to work.

Participants who had gone through the process viewed the return to work policies positively. Two individuals wanted to go back to work earlier than outlined by the occupational health department:

“They actually drew up a programme for me, a staged return to work which I think was excellent. But within a couple of works I thought I can't be doing with this so I then said can I come back to work full time please".... "But it is up to the individual, it is all done in consultation with the individual so if it's not right for you then they will sort something else out" [Participant 10, male, organization1].

Another participant from organization 2 had been absent for over three months and wanted to return to work because they missed the interaction of the job as well as fearing that they would be out of touch with work once they returned:

"Of course once I was back in to the swing of things even though I was still in a bit of pain I was chomping at the bit to come back for 12 hours but they wouldn't let me. They kept me for a good few months doing two, and then move up to four, and then I moved to six and then eight and they just sort of guided me" [Participant 19, male, organization 2].

It was acknowledged that if employees had been absence from work for several months it could be hard to come straight back to work. Putting individuals on restricted hours allowed them to get used to returning to work by building up the number of hours slowly: 
"It also helps people to get back into the flow of it because if people have a year off then going straight back in for 12 hours, 4 days a week can be quite daunting" [Participant 5, female, organization 1]

\section{Personal Factors}

Attititudes towards presenteeism Employees from both organization 1 and 2 reported that they would attend work if they were unwell. The majority of participants had clear ideas of what health conditions they would take time off work for, for example sickness and diarrhoea, broken limbs etc. Colds, on the other hand were not generally seen as a reason to take sickness absence, although it depended on the severity. Throughout all the interviews the illnesses mentioned were physical in nature, only one participant talked of coming to work with a mental health complaint.

In general employees from organization 2 stated that they rarely felt ill and eight participants could not recall the last time they came into work although they should have stayed home for health reasons. In contrast only two participants from organization 1 could not recall the last time they went into work whilst ill, the remaining ten reported that they went into work despite being unwell or suffering from injuries. Three participants felt that they had returned to work too early. Upon reflection they felt that they would have benefited from further recuperation time, as one participant recalls after a serious illness:

“I didn’t feel particularly 100\%, I wouldn’t say I felt ill any more but I still didn’t feel $100 \%$ I think that dragged on for a couple of more months than it would have been if I had had another month, 6 weeks off work to fully recover at home" [Participant 9, female, organization 1] 
While one participant stated that he made a decision not to come back too early:

"I deliberately refused to come back into work early at that occasion because....I've done it before, I've come back into work even though I wasn't 100\% and I just thought I wasn't going to do it this time" the reason for this was: "because....it doesn't really benefit myself in anyway, coming back early, it means I'm coming back I'm not a $100 \%$ I still am expected to perform at a $100 \%$ and you don't get any thanks at the end of the day" [Participant 3, male, organization 1]

\section{Loss of wages}

The prospect of loss of pay was mentioned by six employees in organization 2 as a factor that encouraged them to come into work despite being unwell, however no one cited it as the only factor. Indeed most participants went on to mention that they rarely were ill:

"Basically it's going to have to be something pretty severe like a broken leg, or the onset of Malaria of something like that to stop me from coming in here because at the end of the day I've got to pay the bills and that's it" [Participant 27, male, organization 2]

Taking time off sick as holiday was an option which two participants had taken to mitigate against lost wages:

[My team leader] said I could have some days off as holiday, but if he hadn't of said that then I would have had to come to work and carried on with it. [Participant 27, male, organization 2]

Personal motivation for presenteeism 
Participants from both organizations talked about their personal motivation to come into work whilst feeling unwell or with an injury. Such motivation differed across participants and included personal drivers such as a personal work ethic, not wanting to let colleagues down and wanting to see a project through to conclusion. Often participants highlighted a combination of the reasons above as to why they went into work whilst feeling unwell.

Other motives for coming to work whilst unwell include wanting to go to a course or wanting to make a good impression having just joined the police or wanting to see a project through to conclusion:

"I'd worked on the (project) for five months and you know when you put your heart and soul into something...it was just really important to me to sort of not let other people take over my work when I'd put my heart and soul into it for so long" [Participant 6, female, organization 1]

The nature of work carried out by organization 2, namely food production, meant that there were certain illnesses such as gastroenteritis, diarrhoea and sickness that staff were not allowed to come to work with. However, most employees, managers and non-managers, stated their commitment to come into work if they did not have a restricted illness but felt ill:

"Sometimes I think I don't really want to go in, but of course you do once you get here get on with it, that's it. I think its pride and I think the longer you work for a company...you don't take so much time off' [Participant 22, male, organization 2]

Around a quarter of participants, from both organizations, discussed personal motives amounting to a personal work ethic. This work ethic resulted from a number of reasons such as parental upbringing, age or personal pride that made them committed to going to work despite being ill: 
“I don't like letting other people down and that's just me personally I don't know whether that's just the way I've been brought up or what" [Participant 11, male, organization 1]

\section{Impact of sickness on colleagues}

One of the main concerns expressed by participants about individuals coming to work whilst ill was that they would pass contagious illnesses on to their colleagues.

"Yes we're on a very small unit"........ "And if someone was to come in and they are contagious it could have a major impact on the unit because it would decimate us if everybody went off sick" [Participant 10, male, organization 1].

Interestingly, although participants stated that they would come into work with illnesses such as colds they did not want to be infected by others coming into work with such ailments. For example one participant stated that while they would go in to work with a "stinking" cold it:

"really annoys me when people come in with stinking colds and lot of them do it and you think well you're just going to shove it around the office or if you are sitting in a car with that person for 9 hours there's a good chance you're probably going to get it as well but we're all guilty of it" [Participant 11, male, organization 1].

It was recognised by some participants that individuals who were ill sometimes had a dilemma in terms of risking coming into work and passing the illness on to colleagues or taking time off and leaving the team or department short staffed:

"I suppose the flu season or something like that, it spreads like wild fire and you kind of have this damned if you do, damned if you don't kind of attitude in your head, where if you don't come in you are leaving your colleagues short but if you do come 
in there's the chance that they're going to then get ill and be too ill to work" [Participant 3, male, organization 1].

It was recognised by participants that help each other out when someone felt unwell. One participant from organization 1 recalled that when he hurt his back his colleagues helped him by taking over the job of breaching a locked door using a battering ram because he was not fully recovered from a back injury. Another participant acknowledged the help of colleagues:

"I think there's just sort of a general attitude of ...you come in unless ...well I'd say unless you're dying, so to speak and people will compensate for that because they're your colleagues and they have been in that situation themselves before, they will cover for some of your short falls whilst you are ill...it's sort of an unofficial understanding that seems to go on" [Participant 3, male, organization 1].

"If I couldn't have done all of my job there was other people who could help me"” [Participant 16, female, organization 2]

However not all participants were happy to do this:

"As horrible as it sounds you shouldn't have to keep an eye on your colleagues, if they're ill they should be able to either cope with the situation and get on with the job or if they're that bad then go home and see a doctor" [Participant 13, female, organization 1].

Participants from both organizations stated that they did not want to let their colleagues down who they perceived as having to cover their job if they were absent. As one participant said "I just feel if I'm not there then other people are having to pick up the work load" [Participant 8, female, organization1]. 
Across both organizations there was not the extra staff to take on any staffing short fall so that if an individual did take time off it resulted in an extra burden on their colleagues:

"We work in an office based environment and all the work comes in and we have to do it, just if there's one less person there's more work to do, more pressure to get it done" [Participant 8, female, organization 1]

"I'm part of a team they can't really do without me or they would struggle" [Participant 20, male, organization 2]

Although temporary staff may be brought in at organization 2 they need chaperoning which takes up time:

"or they're going to be a person short on the line and it's just harder work for everyone else so yes there is a big consequence" [Participant 24, female, organization 2]

\section{Discussion}

The aim of this study was to explore the personal perceptions and beliefs participants held about presenteeism and sickness absence. Our findings revealed that organization 2, a private sector organization, had higher levels of job satisfaction, lower absenteeism and lower presenteeism levels in relation to organization 1. The participants in our study had differing personal motivation towards, and perspectives on, presenteeism and absenteeism and our findings illustrate the fact that there are a number of underlying reasons why people come into work whilst unwell. Coupled with personal motivation our findings suggest that the work environment is also important. This supports the view that organizational and personal context is important when considering presenteeism and that a combination of factors is likely 
to support or mitigate employee presenteeism (e.g. Dew et al., 2005; Baker-McClearn et al., 2010).

Our findings highlight that participants from both organizations had personal motivation to come into work whilst being ill or with an injury, for example finishing off a work project or going on a course. With organization 2 it could be argued that the prospect of losing pay would play an important role in encouraging people towards presenteeism and six employees did cite this as a factor. However, personal motives similar to a personal work ethic emerged from the data from both organizations. Indeed, a manager at organization 2 commented on the fact that there was a 'general work ethic' at the company which he had not previously seen in other food factories. Previous research has indicated that workplace culture can reinforce a work ethic as certain views are passed from employee to employee (BakerMcClearn et al., 2010). The findings from this study suggest that some employees may join an organization with a personal work ethic derived from their upbringing, age or previous employment. These individuals may then influence group norms towards presenteeism (Bamberger and Biron, 2007) through peer relationships.

Motivation towards presenteeism is also likely to be influenced by the working environment. For example, our findings support previous research by Grinyer and Singleton (2000:13) which found that being a team member "instilled an obligation to fellow team members which resulted in a reluctance to take sick leave”. Participants from both organizations talked about the consequences to their colleagues of their actions. If they took sick leave they were concerned that they would add to the workload of their colleagues whilst if they came into work unwell they were worried about spreading their illness amongst their work colleagues. Thus, some employees experience a push/pull dilemma in respect of whether to take leave when unwell or come into work and risk affecting others. Although 
participants reported coming to work despite being ill there was recognition that they themselves did not want to be infected by ill colleagues.

However, it is also noteworthy that work tasks in both organizations required the collaborative effort of highly dependent groups, in that poor performance (or absence) in one area affected the task accomplishment of others in the group. As quotes from the interviews highlight this puts pressure on individuals towards presenteeism because they do not want to let colleagues down or put an extra work burden on them. In organization 2 there were also work areas that were characterised by low dependency groups and data from the interviews tentatively suggests that not having dependent work colleagues may make a difference to whether people take time off sick. This is an interesting area of research as it is likely that not all teams will react in the same way and it is unclear whether low dependency teams differ from high dependency groups in terms of presenteeism and this area would benefit from future research.

Other aspects of the working environment are also likely to influence absenteeism and presenteeism levels. Organization 2, which had lower presenteeism, lower absenteeism and higher job satisfaction than organization 1, promoted health and well being extensively and had introduced a number of health initiatives which were well regarded by participants. Participants acknowledged that the health and well being stance taken by the organization was very positive and that the company did care for people's well being and this may have increased job satisfaction. In contrast, the higher presenteeism in organization 1 is likely to have been promoted to an extent by the higher absenteeism as having people absent puts a greater work burden on colleagues. Coupled with tight staffing levels it may reinforce an individual's belief that they should go into work, despite being ill, as they do not want to further increase the work burden on their colleagues. 
Participants acknowledged that co-workers helped individuals who came to work whilst ill or injured with aspects of the job that they could not do. Although this can be an additional work burden to employees, in some respects helping an individual in this way is more beneficial to co-workers because if the individual did not get the support they may take sick leave and colleagues would have to take on more work.

The sickness absence polices of the two companies did have some similarities for example they both used 'trigger points' to monitor sickness. Consistent with previous research by Grinyer and Singleton, (2000) our findings illustrate how attendance management mechanisms put in place by the organization can lead to absenteeism. Participants were reluctant to risk taking two periods of sickness off, ensuring they were fully recovered before coming back to work. However, although organizational policies towards sickness absence are fairly similar interpretation of them can vary. Some employees who have returned to work before they were fully recovered have been sent home by managers before accruing a second absent period, while other individual's were allowed to do so. Employees, particularly from organization 1, who had attempted to come back to work before they were fully well felt that such a system was unfair and penalised staff, especially if they subsequently need to take more time off for the same health condition. Overall, organizational polices are an important work-related factor for presenteeism and need to be considered as part of any future research as well as a wider range of personal and dispositional characteristics.

Our findings indicate that well designed and managed return to work policies can be of reciprocal benefit to both the organization and the employee supporting previous research by Baker-McClearn, (2010). It was acknowledged that employees returning to work through modified duties or graded return to work policies would be less productive but it helped the organization in the long term because they retained trained and experienced staff and allowed employees to retain their skills and their self-confidence within the work place. Participants 
who went through the process viewed the policies positively. Thus, there are two facets to presenteeism: one where it is acknowledged that the individual is not working at full production as the organization and employee work together to return to work after an absence; and the another facet which is likely to be for short terms in which the individual comes to work despite being ill because of organizational or personal reasons and the organization is likely to remain unaware that an individual is not working at full capacity.

\section{Conclusion}

This research has explored the factors that influence an individual's decision to come into work despite being ill providing further evidence that context is important. Our findings highlight the importance of both the work environment and an individual's personal motivation on presenteeism behaviour. Thus an employee's decision to come in to work whilst ill is likely to be based on consideration of a combination of factors.

Our findings suggest that presenteeism is affected by personal motivation such as work ethic. Differences in work ethic may be generational as increasingly people entering the work force have less emphasis on hard work while valuing flexible working (Smola and Sutton, 2002; Cennamo and Gardner, 2008). This area would benefit from further research as organizations may need to adapt their sickness absence policies and monitoring procedures to encompass this growing trend. Another area for future research is the effect of teams on presenteeism with respect to the interaction of high versus low dependency teams. 


\section{Limitations}

The qualitative approach adopted in this research allowed a rich exploration of the factors underlying presenteeism. Although the inclusion of one public sector organization and one private sector organization allows us to compare across sectors we cannot assume that our findings can be generalised more widely. Both organizations that took part in this study were very proactive in terms of health and well being and therefore cannot be deemed to be representative of organizations across the UK. As this study has revealed context is important to presenteeism and further research would need to include small and medium organizations in different sectors to understand whether the contextual issues found in this study are of importance across smaller organizations especially as they may not have access to Occupational Health expertise. 


\section{References}

Aronsson, G., Gustafsson, K. And Dallner, M (2000) "Sick but yet at work. An empirical study of sickness presenteeism". Journal of Epidemiology and Community Health, 54:502509.

Aronsson, G., Gustafsson, K. (2005) "Sickness presenteeism: Prevalence, attendance-pressure factors, and an outline of a model for research". Journal of Occupational EnvironmentalMedicine, 47:958-966

Ashby, J. and Mahdon, M. (2010) "Why do employees come to work when ill? An investigation into sickness presence in the workplace". The work foundation http://theworkfoundation.com/Assets/Docs/Axaevents/FINAL [accessed 10 August 2011]

Baker-McClearn, D., Greasley, K., Dale, J. and Griffith, F. (2010) “Absence management and presenteeism: the pressures on employees to attend work and the impact of attendance on performance". Human Resource Management Journal 20(3):311-328.

Bamberger, P. and Biron, M (2007) "Group norms and excessive absenteeism: The role of peer referent others". Organizational Behaviour and Human Decision Processes, 10, pp.179196.

Bockerman, P. and Laukkanen, E. (2009) "What makes you work while you are sick? Evidence from a survey of workers". European Journal of Public Health, 20(1):43-46.

Cartwright, S. and Cooper, C. L. (2002) “ASSET: an organizational stress screening tool”. Robertson Cooper Limited and Cubiks, London

Calverley, N., Barton Cunningham, J., and MacGregor, J. N. (2007) "Sickness presenteeism, sickness absenteeism, and health following restructuring in a public service organization". Journal of Management Studies 44(2):304-319.

CBI/Pfizer (2010) "On the path to recovery: Absence and workplace health survey 2010" http://www.cbi.org.uk/pdf/20100607-cbi-pfizer-absence-report.pdf [accessed 7 December 2010.

Cennamo, L. And Gardner, D. (2008) "Generational differences in work values, outcomes and person-organisation values fit". Journal of Managerial Psychology, 23(8):891-906.

Chatterji, M. And Tilley, C. J. (2002) "Sickness, absenteeism, presenteeism, and sick pay". Oxford Economic Papers, 54:669-687.

Faragher, E. B. (2004) "A shortened stress evaluation tool (ASSET)" Stress and Health, 20:189-201.

Dew, K., Keefe, V. and Small, K. (2005) "Choosing to work when sick: workplace presenteeism". Social Science and Medicine, 60:2273-2282. 
Grinyer, A., and Singleton, V. (2000) "Sickness absence as risk-taking behaviour: a study of organizational and cultural factors in the public sector". Health, risk and Society, 2(1):7-21.

Hansen, C. D. and Anderson, J. H. (2008) "Going ill to work - What personal circumstances, attitudes and work-related factors are associated with sickness presenteeism?" Social Science and Medicine, 67:956-964.

Johns, G (2010) "Presenteeism in the workplace: A review and research agenda". Journal of Organizational Behavior, 31(4): 519-542.

King, N. (2004) "Using templates in the thematic analysis of text". In C.Cassell and G. Symons (eds). Essential Guide to Qualitative Methods in Organizational Research. London:Sage

Leineweber, C., Westerlund, H., Hagberg, J., Svedburg, P., Luokkala, M., and Alexanderson, K. (2010) "Sickness presenteeism among Swedish police officers". Journal of occupational rehabilitation. (published online $9^{\text {th }}$ June 2010)

Ramsey, R. D. (2006) "Presenteeism: a new problem in the workplace". Supervision, 67:1417.

Sainsbury Centre for Mental Health (2007) "Mental health at work: developing the business case". Policy paper 8. London:Sainsbury Centre for Mental Health

Sanderson, K., Tilse, E., Nicholson, J., Oldenburg, B., and Graves, N. (2007) "Which presenteeism measures are more sensitive to depression and anxiety". Journal of Affective Disorders, 101, pp.65-74.

Smola, K., and Sutton, C. D. (2002) "Generational differences: revisiting generational work values for the new millennium". Journal of Organizational Behavior, 23:363-382.

Taylor, P., Cunningham, I., Newsome, K., and Scholarios, D. (2010) “"Too scared to go sick' - reformulating the research agenda on sickness absence". Industrial Relations Journal, 41(4):70-288.

Warr, P. (1990) "The measurement of well-being and other aspects of mental health". Journal of Occupational Psychology, 63,193-210.

Wynne-Jones, G., Buck, R., Porteous, C., Cooper, L., Button, L. A., Main, C. J. and Phillips, C. (2010)"What happens to work if you're unwell? Beliefs and attitudes of managers and employees with musculoskeletal pain in a public sector setting" Journal of Occupational Rehabilitation. (published online $4^{\text {th }}$ July 2010). 
Table 1 Absenteeism, presenteeism and job satisfaction by organization

\begin{tabular}{|l|c|c|}
\hline & $\begin{array}{c}\text { Organization 1 } \\
\mathrm{N}=273\end{array}$ & Organization 2 \\
\hline $\begin{array}{l}\text { Absenteeism - self-rated absence } \\
\text { through illness or injury over last } \\
\text { three months }\end{array}$ & $34 \%$ & $14 \%$ \\
\hline $\begin{array}{l}\text { Presenteeism - occasions individual } \\
\text { came into work while sick or injured } \\
\text { during last three months }\end{array}$ & $51 \%$ & $30 \%$ \\
\hline & Mean (SD) & Mean (SD) \\
\hline $\begin{array}{l}\text { Job satisfaction - lower score }= \\
\text { higher job satisfaction }\end{array}$ & 26.67 (12.42) & 23.56 (11.17) \\
\hline
\end{tabular}

